\title{
Contracampo
}

\section{Transmidiação e cultura participativa: pensando as práticas textuais de agenciamento dos fãs de telenovelas brasileiras ${ }^{1}$}

\author{
Transmediation and participatory culture: thinking about \\ the textual practices of mediation of Brazilian telenovelas fans
}

ste artigo é uma versão revista e atualizada do trabalho apresentado no XXIII Encontro Anual da Compós, na Universidade Federal do Pará, Belém, realizado de 27 a 30 de maio de 2014. Consiste também numa etapa inicial do projeto "Cultura participativa e práticas transmídias na teledramaturgia da Globo", desenvolvido junto ao Obitel Brasil.

FECHINE, Yvana. Transmidiação e cultura participativa: pensando as práticas textuais de agenciamento dos fãs de telenovelas brasileiras. In: Revista Contracampo, v. 31, n. 1 , ed. dezembro-março ano 2014. Niterói: Contracampo, 2014. Págs: 5-22.

DOI: $10.5327 / \mathrm{Z} 22382577201400310694$

Enviado em: 11 de nov. de 2014

Aceito em: 30 de nov. de 2014

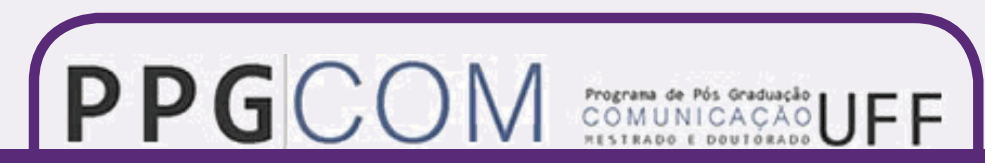

Transmidiação e cultura participativa

Contracampo e-ISSN 2238-2577

Niterói (RJ), v. 31, n. 1, dez-mar/2014 www.uff.br/contracampo

A Revista Contracampo é uma revista eletrônica do Programa de PósGraduação em Comunicação da Universidade Federal Fluminense e tem como objetivo contribuir para a reflexão crítica em torno do campo midiático, atuando como espaço de circulação da pesquisa e do pensamento acadêmico. 


\section{Resumo}

A digitalização e a convergência de meios inseriram a televisão na era da transmidiação, que é entendida como um modelo de produção orientado pela distribuição em distintas mídias e plataformas tecnológicas de conteúdos associados entre si e cuja articulação está ancorada em estratégias e práticas interacionais propiciadas pela cultura participativa. Em uma etapa anterior de pesquisa, foram identificadas e categorizadas as estratégias transmídias adotadas pela televisão brasileira na produção de telenovelas. Como elas convocam algum tipo de participação dos fãs telespectadores, resta ainda o desafio de inventariar e analisar o modo como eles se relacionam com os conteúdos transmídias disponibilizados pelos produtores. Neste artigo, foram problematizadas noções que parecem interligadas e preliminares ao processo de observação empírica dessas relações: cultura participativa, fãs e práticas textuais do agenciamento de conteúdos.

Palavras-chave: transmidiação; cultura participativa; práticas textuais.

\section{Abstract}

The digitalization and convergence of mediums have included television into the era of transmediation, which is understood as a production model guided by the distribution in various medias and technological platforms of associated contents, whose articulation is based on international strategies and practices that use participatory culture. In a previous stage of this research study, we identified and categorized the transmedia strategies adopted by the Brazilian television in the production of telenovelas. Because these strategies stimulate some participation from the television-viewers fans, we are faced with the challenge of categorizing and analyzing the way they associate with transmedia contents made available by the producers. In this article, notions that we think are interrelated and that are preliminary to the process of empirical observation are discussed, namely: participatory culture, fans, and textual practices of mediating contents

Keywords: transmediation; participatory culture; textual practices. 


\section{Transmidiação e televisão transmídia: contexto de pesquisa}

digitalização e a convergência de meios têm provocado reconfigurações significativas
na indústria televisiva. Muitos estudiosos da televisão já adotam a expressão “televisão transmídia”, referindo-se a uma lógica de produção, distribuição e consumo de conteúdos televisivos, apoiada nas propriedades técnico-expressivas das mídias digitais e nas possibilidades por elas abertas de uma maior participação do espectador ${ }^{2}$. O envolvimento do espectador é, a um só tempo, uma condição e também o objetivo das experiências de transmidiação que temos analisado na ficção televisiva brasileira. Em trabalhos anteriores (FECHINE, 2013; FECHINE et al. 2013), a "transmidiação" foi definida como um modelo de produção orientado pela distribuição em distintas mídias e plataformas tecnológicas de conteúdos associados entre si, e cuja articulação está ancorada em estratégias e práticas interacionais propiciadas pela cultura participativa estimulada pelos meios digitais. Para os estudiosos do fenômeno, o desafio consiste, então, em identificar e analisar quais são essas estratégias e práticas, as quais variam de acordo com o campo de produção (teledramaturgia, jornalismo, publicidade etc.).

Na perspectiva que adotamos, as estratégias transmídias são oriundas necessariamente de uma instância produtora que, ao mesmo tempo em que faz um apelo à participação, quer mantê-la, de algum modo, "sob controle". Para isso, esforça-se para criar e ofertar os próprios espaços e as condições de participação. Na maioria dos projetos bem-sucedidos, essa instância corresponde a uma empresa, corporação ou conglomerado de mídia. No caso específico da televisão brasileira, tal instância produtora pode ser identificada com organizações de comunicação que detêm a concessão das emissoras de televisão, mas também atuam com rádio, jornais e Internet, como é o caso da Rede Globo.

Desde 2010, a Rede Globo investe sistemática e assumidamente em ações transmídias nas telenovelas, tornando-se, por isso, um objeto privilegiado de estudo do Observatório Ibero-americano de Ficção Televisiva (Obitel) no Brasil. Como parte de um projeto temático e coletivo de pesquisa, desenvolvido no Obitel, no biênio 2012-2013, acompanhamos e inventariamos a produção de conteúdos transmídias em torno das telenovelas da Globo (frutos da articulação entre os capítulos exibidos na televisão, do site oficial da telenovela

\footnotetext{
2 Cf, por exemplo, Evans (2011).
} 
e de um perfil no Facebook) (cf. LOPES, 2013). De modo geral, esses conteúdos obedecem a duas grandes estratégias, a propagação e a expansão, descritas em trabalhos anteriores ${ }^{3}$.

A chave da estratégia transmídia denominada de propagação é a ressonância, a retroalimentação dos conteúdos. Um conteúdo repercute ou reverbera o outro, colaborando para manter o interesse, o envolvimento e a intervenção criativa do consumidor de mídias no universo proposto, agendando-o entre outros destinatários ou instâncias, constituindo comunidades de interesses. Trata-se, muito frequentemente, de uma estratégia destinada a repercutir um universo narrativo em redes sociais na web ou fora dela, acionando o gosto dos consumidores por saberem mais sobre aquilo que consomem nas mídias. As estratégias de propagação são orientadas, no caso das telenovelas, por exemplo, pelo objetivo de reiterar e repercutir conteúdos das telenovelas entre plataformas, promovendo um circuito de realimentação do interesse e da atenção entre eles (TV e Internet, especialmente, no caso das telenovelas). Forma-se, desse modo, um ciclo sinérgico, no qual um conteúdo chama atenção sobre o outro, acionando uma produção de sentido apoiada, em suma, nessa propagação por distintos meios de um determinado universo narrativo.

Já as estratégias de expansão envolvem procedimentos que complementam e/ou desdobram o universo narrativo para além da televisão. Consistem, assim, em "transbordamentos" do universo narrativo a partir da oferta de elementos dotados, por um lado, de uma função lúdica e, por outro, de uma função narrativa propriamente dita. Neste primeiro caso, promove-se, inclusive, a extração de elementos do universo narrativo para o cotidiano da audiência, por meio de conteúdos que estimulam o espectador a fabular, vivenciar ou entrar em um jogo de "faz de conta" a partir do seu envolvimento com os personagens e as situações apresentadas. No último exemplo, investe-se na proposição de extensões textuais em plataformas associadas, tendo como referência a construção de uma transmedia storytelling, tal como descrita por Jenkins $(2003,2008,2009)$. Investe-se na complementaridade entre elementos e programas narrativos interdependentes, porém dotados de sentidos em si mesmos. Há, portanto, uma organicidade entre os conteúdos postos em circulação e disponíveis para acesso dos agentes criativos (consumidores). Essa interdependência e organicidade entre os eventos distribuídos nos diferentes meios é o que nos permite enxergar o conjunto como um tipo particular de

\footnotetext{
3 A descrição dessas estratégias, feita a seguir, retoma as postulações apresentadas em uma etapa anterior da pesquisa. A recuperação de alguns conceitos é necessária aqui, mas precisa ser condensada. Para maior aprofundamento, consulte Fechine et al. (2013).
} 
narrativa que investe na integração entre meios para propor aprofundamentos a partir de tal distribuição articulada de conteúdos. Os distintos modos de expansão do universo podem ser considerados, nas ações mais complexas, como programas narrativos auxiliares ou secundários, contribuindo, a partir da sua articulação, com o programa narrativo principal ou de base (texto de referência), para a construção de uma narrativa transmídia stricto sensu.

A partir dessas duas estratégias, foi possível categorizar os conteúdos transmídias produzidos em torno de novelas exibidas pela Rede Globo entre 2012 e $2013^{4}$. Foram identificadas na observação: duas categorias de conteúdos transmídias de propagação — reformatados e informativos - que se desdobraram em cinco subcategorias (conteúdos de antecipação, recuperação, remixagem, contextuais e promocionais); duas categorias de conteúdos transmídias de extensão - de extensão textual e lúcida — que se desdobraram, por sua vez, em mais quatro subcategorias (extensões narrativas, diegéticas, vivências e de marca). Não cabe, nos limites deste artigo, a descrição e o detalhamento dessa categorização que pode ser encontrada em Fechine et al. (2013). O exercício de observação e análise dos conteúdos resultantes das estratégias transmídias evidenciou, no entanto, a necessidade de desdobrarmos o trabalho, observando, agora, as “convocações" ou demandas de participação feitas por cada uma delas ao consumidor de mídias. Se, como postulamos antes, a transmidiação é um fenômeno ancorado em uma cultura participativa, é possível concluir que, subjacente a essas "estratégias", existem "práticas textuais" do consumidor de mídias que também precisam ser igualmente inventariadas e analisadas. É esta a próxima etapa do trabalho, cuja base conceitual começa a ser esboçada aqui, discutindo noções que nos parecem interligadas e preliminares ao processo de observação empírica: cultura participativa, fãs e práticas textuais do agenciamento de conteúdos.

\section{Cultura participativa e fãs}

"Cultura da participação" ou "cultura participativa" são expressões empregadas com várias acepções e em abordagens de distintas áreas (Comunicação, Educação,

\footnotetext{
4 A categorização mencionada surgiu do acompanhamento sistemático dos capítulos exibidos na televisão, bem como do site e dos perfis oficiais em redes sociais, com registro em diários informativos. Foram estudadas as seguintes telenovelas: "Amor Eterno Amor", "Lado a Lado", "Cheias de Charme”, “Avenida Brasil", "Gabriela", "Malhação" e "Amor à Vida", além de "Malhação" (também na temporada de 2012).
} 
Marketing, entre outras) $)^{5}$. Fala-se em “cultura participativa” para tratar de ações transmídias, fandom, jornalismo cidadão, ativismo político e engajamento cívico nas mídias digitais. Atualmente, a expressão "cultura participativa" é utilizada para abordar de um leque tão grande de manifestações que mais adequado seria nos referirmos a "culturas participativas", realçando a ideia de que não estamos diante de um fenômeno único nem tampouco de um conceito monolítico. Estamos, ao contrário, perante um mosaico de manifestações sustentadas pelo desejo de uma intervenção mais direta nos processos, quer sejam eles de caráter político, quer sejam motivados pelo consumo cultural.

Na discussão proposta, assumiremos como referência as ideias de Henry Jenkins (2006), o qual também reconhece a participação como uma propriedade da cultura, mas faz um uso mais restrito dessa expressão, empregando-a para descrever a explosão das tecnologias digitais interativas que possibilitaram aos consumidores médios registrar, arquivar e produzir conteúdos de mídia, operando como agentes fundamentais na sua circulação. Jenkins (2006) entende a cultura participativa como um fenômeno no qual há criação e compartilhamento de conteúdos entre os consumidores de mídia, motivados pela crença de que as suas contribuições importam para os outros. Nesse processo de compartilhamento, os participantes são munidos de algum grau de conexão social com os outros, o que, em muitos casos, estimula inclusive engajamentos cívicos. Jenkins (2008) preconiza que a cultura participativa é movida por uma inteligência coletiva, que constrói um acervo comum e em rede, a partir da doação que cada um faz do seu próprio conhecimento e experiência.

Nem todos os membros precisam contribuir, mas todos devem acreditar que são livres para contribuir quando estiverem prontos e que suas contribuições serão devidamente valorizadas. Em tal mundo, muitos vão se envolver mais superficialmente, alguns vão cavar mais fundo, e outros ainda vão dominar as habilidades que são mais valorizadas dentro da comunidade. A própria comunidade, no entanto, fornece fortes incentivos para a expressão criativa e a participação ativa. (JENKINS, 2006, tradução livre).

\footnotetext{
5 Cf., por exemplo, Jenkins (1992, 2006, 2008), Shirky (2011), Delwiche e Henderson (2012).
} 
Jenkins (2006) lembra que muitos jovens já fazem parte desse processo de participação, adotando novas formas de:

- filiação, por meio da criação ou operação em associações (formais e informais) e comunidades on-line, como Facebook, MySpace e fóruns;

- expressão, produzem novas formas criativas, tais como fan fiction, fan vídeo, fanzines, mash-ups etc.;

- colaboração na resolução de problemas, ou seja, trabalham juntos em equipe, formal e informalmente, para concluir tarefas e desenvolver novos conhecimentos, como na Wikipédia;

- circulação, interferem nos fluxos de mídia (por meio de podcasting, blogs etc).

O que Jenkins, Ford e Green (2013) entendem como cultura participativa corresponde, em suma, aos modos como as comunidades em rede interferem na produção e circulação de conteúdos midiáticos. No caso específico da televisão, em que as tecnologias interativas são mais limitadas, a cultura participativa manifesta-se por meio da reorganização da programação (seu consumo não linear, por exemplo), da reoperação dos conteúdos em outras mídias/plataformas (disponibilização, manipulação), de comentários sobre os programas exibidos na televisão em redes sociais (um modo de assistir juntos à programação, mas virtualmente), da transmidiação.

Com base nas postulações de Jenkins, temos tratado como "cultura participativa" o cenário e conjunto variados de possibilidades abertas aos consumidores de maior acesso, produção e colocação em circulação de conteúdos midiáticos, a partir da digitalização e convergência dos meios (FECHINE, 2013). A cultura participativa define, nessa perspectiva, novas práticas de uso das mídias associadas, sobretudo, ao compartilhamento, à publicação, à recomendação, aos comentários, ao remix e à reoperação de conteúdos digitais (criados e disponibilizados em meios digitais, especialmente na Internet). No contexto específico da transmidiação, Jenkins (2008) destaca como esse ambiente de convergência propicia, por um lado, a fluidez com que o conteúdo midiático passa por diferentes plataformas e, por outro, a capacidade do público de empregar redes sociais para se conectar de maneiras novas, moldando ativamente a circulação desse conteúdo e desenvolvendo habilidades tanto para filtrar quanto para se envolver amplamente com os produtos espalhados nas distintas mídias. Para Jenkins (2008), os consumidores são agentes criativos fundamentais na constituição do universo ficcional transmídia, pois são quem, ao atenderem o convite 
para estabelecerem essas conexões, definem não apenas os usos das mídias, mas também o que efetivamente circula entre elas.

Inicialmente, a expressão cultura participativa foi utilizada por Jenkins para designar especificamente a produção cultural e as interações sociais entre fãs das demais comunidades em rede e outras formas de consumo midiático nos meios digitais (JENKINS, 1992; JENKINS; FORD; GREEN, 2013). Somente depois, o termo passou a ser empregado para tratar da produção e distribuição dos conteúdos de modo colaborativo também por outras comunidades de interesse. Não há, no entanto, como dissociar a cultura participativa do fandom, termo que designa justamente as práticas coletivas dessas comunidades de fãs que, tirando proveito das tecnologias digitais interativas, compartilham interesses e conteúdos por um determinado programa ou personagem (BOOTH, 2010, p. 2). Jenkins (1992, p. 77) ressalta que muitas práticas do fandom estão ancoradas no desejo de estar ou sentir-se junto a outros que apreciam e estão dispostos a se envolver com ou em um mesmo universo lúdico. Quando se fala em fandom, o que está em questão não é apenas o comportamento individual de um fã, mas uma experiência coletiva de consumo de mídia em torno de um determinado objeto, razão pela qual o compartilhamento é fundamental para entendê-lo. Para o mesmo autor, o fandom é, portanto, uma das manifestações mais representativas da cultura participativa (JENKINS, 1992).

Se o envolvimento é, a um só tempo, a condição e uma das consequências das estratégias transmídias, nada mais natural que estas tenham como foco os fãs. Quando falamos em $f a ̃$, no entanto, mais uma vez não estamos diante de um conceito monolítico. Genericamente, ele é todo sujeito que está emocionalmente comprometido e demonstra um engajamento regular com um determinado objeto (pessoas, narrativas, textos) (SANDVOSS, 2013, p. 9). O fã investe tempo e energia interagindo com um objeto de mídia existente e que lhe encanta (BOOTH, 2010, p. 11). A intensidade desse envolvimento molda diferentes práticas a partir das quais seus estudiosos estabelecem distinções. A tipologia de fãs proposta no trabalho de Abercrombie e Longhurst ${ }^{6}$, uma das mais conhecidas entre os estudiosos do fandom, foi retomada por autores como Sandvoss (2013) e Duffett (2013). Ambos admitem que essas práticas definem-se entre os polos do mero consumo e da produção própria de conteúdos. Entre essas duas polaridades, definem-se três grupos que podem receber

\footnotetext{
6 A obra que lhes serve de referência é: ABERCROMBIE, N.; LONGHURST, B. Audiences: A Sociological Theory of Performance and Imagination. London: Sage, 1998.
} 
denominações diferentes, mas possuem descrições muito próximas. Sandvoss (2013), por exemplo, menciona "fãs", "entusiastas" e "adoradores":

O primeiro grupo, "fãs", acompanha intensamente um texto ou ícone cultural determinado quase com exclusividade por meio da mídia de massa. Eles fazem parte de um público pulverizado e não estão vinculados um ao outro em um patamar organizacional. Já o uso das mídias pelos adoradores é mais especializado, assim como o seu objeto de fandom. Além disso, eles tendem a desenvolver laços, mesmo que amplamente desorganizados, com outros que partilham esse fandom. No caso dos entusiastas, enfim, o que importa não é tanto o objeto de fandom mediado pelos meios de comunicação de massa (como, por exemplo, um determinado pop star, um programa televisivo ou time de futebol), e sim a sua própria atividade e produtividade textual, que constituem o cerne do fandom. Os entusiastas consomem textos altamente especializados que são produzidos por outros entusiastas, como os fanzines, que são trocados por meio de estruturas organizacionais como as convenções de fãs, fã-clubes ou comunidades on-line. (SANDVOSS, 2013, p. 26).

Sandvoss (2013, p. 27) admite que o primeiro grupo, denominado "fãs", constitui a grande maioria dos consumidores de mídia7. Embora haja, segundo ele, "um número significativamente menor de adoradores e ainda menor de entusiastas" (SANDVOSS, 2013, p. 27), são as suas práticas que definem o que já se tornou conhecido como uma “subcultura de fãs". Duffett (2013) admite a existência das mesmas distinções entre os grupos, mas previne que emprega em sua obra o termo "fã", de modo mais livre, como sinônimo do que outros autores descrevem como "entusiastas", assumindo que são eles os responsáveis pelo fandom, seu objeto de estudo.

Pensando especificamente na televisão, Jenkins (2008, p. 109) também admite a existência de três grupos de consumidores de conteúdos: zapeadores, casuais e fiéis. Os primeiros mudam constantemente de canal, assistindo fragmentos de programas sem envolvimento

\footnotetext{
7 Os fãs são "consumidores ideais" de mídia: buscam sempre mais, participam de promoções e eventos, compram produtos relacionados, formam um mercado relativamente estável e de nicho na cultura de massa (DUFFETT, 2013, p. 25).
} 
com os conteúdos. Os últimos "entregam-se" aos programas, repercutem o que consomem e costumam buscar mais conteúdos relacionados em outras mídias. Os casuais encontram-se no meio termo entre zapeadores e fiéis: assistem aos programas sem a inconstância dos zapeadores, mas também sem o compromisso dos fiéis. São esses espectadores que correspondem, em princípio e de modo mais geral, ao que compreendemos aqui como fãs telespectadores. Os fiéis assistem aos programas com regularidade e atenção especial, e, frequentemente, mais de uma vez, observando os pormenores, dosando sua proximidade emocional com certo distanciamento crítico. Para os fãs telespectadores, assistir a um programa é apenas o começo, e não o fim do processo de consumo de mídia (JENKINS, 1992, p. 284).

Independentemente das terminologias empregadas, o importante é que, para esses estudiosos, o conceito de fã está sempre associado a algum tipo de "consumo ativo" (JENKINS, 1992, p. 284), ou seja, que pressupõe algum tipo de agenciamento sobre os conteúdos. Este consiste em várias formas de intervenção sobre aquilo que consomem e em distintos graus de envolvimento com os conteúdos: eles decidem onde, quando e como consumir os conteúdos ofertados; atendem aos pedidos de colaboração dos produtores; enviam retorno aos produtores por meio das redes sociais, afirmando seu direito de fazer julgamentos e expressar opiniões sobre o desenvolvimento de seus programas favoritos e, nas experiências mais bem extremas de engajamento, constituem comunidades e produzem seus próprios conteúdos a partir dos objetos existentes.

O fã é, em suma, um tipo particular de consumidor de mídia identificado a determinadas práticas, dentre as quais as adotadas pelo fandom podem ser consideradas como expressões máximas de envolvimento (fan fiction, fan videos, fan art, fanzines etc.). No caso particular da transmidiação, ele pode ser pensado como um tipo de consumidor que se dispõe a realizar o "trabalho" de cooperação textual proposto pelos produtores, um "trabalho" sem o qual o texto transmídia não se realiza como tal visto que sua manifestação depende de relações, conexões e associações por fazer. Esse "trabalho" corresponde ao que denominamos de práticas textuais, indicando com o qualificativo (textuais) um tipo de prática diretamente associada ao agenciamento sobre ou a partir dos conteúdos ${ }^{8}$. É delas que trataremos a seguir, a partir da observação continuada que temos feito do fenômeno da transmidiação na teledramaturgia da Rede Globo.

${ }^{8}$ Essa distinção é importante porque há uma variedade muito grande das práticas de fãs e nem todas interessam diretamente à nossa abordagem. 


\section{Transmidiação e práticas textuais de agenciamento}

Definimos anteriormente a transmidiação como um modelo de produção multiplataforma, que opera a partir de estratégias e práticas interacionais propiciadas pela cultura participativa. Essas correspondem, em sentido mais estrito, às práticas textuais do agenciamento de conteúdos, e remetem, genericamente, aos modos de relação dos fãs espectadores com os conteúdos transmídias e, mais especificamente, às modalidades de "trabalho" com os “textos transmídias" exigidos dos fãs espectadores como parte das estratégias traçadas pelos produtores. Consideramos que há, nessas relações, um processo de determinação recíproca: o telespectador torna-se fã no momento em que se dispõe a "trabalhar" com o texto, do mesmo modo que este só assume sua condição de transmídia quando consegue, a partir justamente das estratégias propostas pelos produtores, colocar o telespectador para "trabalhar".

Tal "trabalho" ao qual nos referimos aqui não se confunde com as práticas de "leitura" e interpretação crítica, que se constituem em objeto dos estudos de recepção, especialmente na tradição brasileira de investigação das telenovelas. Não estamos tratando, portanto, de uma "cooperação interpretativa" por meio da qual os fãs espectadores produzem uma pluralidade de sentidos determinada não apenas pela materialidade e estrutura textuais, mas pelas condições sociais e própria interação com outros consumidores fiéis do programa. Estamos interessados em um tipo de prática na qual esse "trabalho" - uma "cooperação textual" - do fã telespectador é parte daquilo que constitui o texto transmídia como tal, considerando aqui como texto toda e qualquer forma de manifestação de um determinado conteúdo. Textos transmídias, portanto, dependem das práticas textuais de agenciamento. Antes de descrevê-las, cabe, no entanto, definir melhor a natureza desse texto transmídia que tem como uma de suas propriedades básicas a hipertextualidade 9 .

A hipertextualidade pode ser pensada, em termos mais amplos, como um modo de organização da linguagem baseado na remissividade entre textos, ou seja, os textos podem ser associados entre si a partir de pontos de conexão ${ }^{10}$ propostos pelos produtores, mas ativados pelas correlações estabelecidas pelos leitores. Manifestações hipertextuais podem ser pensadas, portanto, como formas abertas que existem em estado potencial, pressupondo,

\footnotetext{
9 Em outro contexto argumentativo e termos, Flores e Porto (2012) também tratam da hipertextualidade nas narrativas jornalísticas transmídias.

10 "Nós", links.
} 
no momento de fruição, o trabalho de associação dos leitores (fãs telespectadores, no nosso caso): um trabalho de "finalização" da textualidade sem o qual não se realizam. O texto transmídia pode ser considerado como um tipo particular de manifestação hipertextual que, como tal, explora a potencialização da informação e depende da interatividade para se realizar (atualizar-se). Constitui-se, por isso, em um texto dotado de abertura (por "fazer-se") e que só se manifesta em ato — o ato de agenciamento proposto ao seu fruidor (no caso que nos interessa, um fã telespectador).

Concebido assim, a partir de um modo de existência potencial, o texto transmídia funciona como uma instância englobante que é pressuposta, logicamente, pela existência de um conjunto de unidades englobadas, as quais, empiricamente, correspondem a todos os produtos propostos pelo projeto ao agenciamento do fã espectador. As categorias analíticas englobado/englobante nos ajudam a compreender esse tipo de textualização, na qual o todo apenas pode ser pensado como uma manifestação da relação entre as partes $^{11}$. No caso do projeto televisivo transmídia ${ }^{12}$, isso implica em assumir que o texto transmídia propriamente dito não pode ser identificado em qualquer de suas expressões isoladas - os episódios na televisão ou na web, o site, um perfil no Facebok ou Twitter etc. - , pois opera como uma matriz de textos, cuja existência reside da interação entre eles e de cada um deles com os fãs telespectadores. Nessa perspectiva teórica, a telenovela, objeto específico de nosso interesse, precisa agora ser pensada como um texto transmídia cuja manifestação ocorre por meio dos capítulos exibidos na televisão, dos conteúdos ofertados no site e dos perfis criados nas redes sociais. Não por acaso, a Rede Globo também já incorporou às equipes das telenovelas produtores de conteúdos transmídias, que é um novo perfil profissional dentro dos seus quadros.

No contexto da televisão transmídia, a análise da produção de sentido nos programas televisivos enfrenta agora novos desafios teórico-metodológicos. Se antes o problema metodológico envolvia apenas a necessidade de compatibilizar na análise a relação entre

${ }^{11}$ Em termos semióticos, o enunciado englobante pode ser pensado como uma manifestação que resulta da articulação em ato de um conjunto dos enunciados englobados, cujo modo de existência é virtualizado. Já o enunciado englobado pode ser pensado como cada uma das unidades que compõe o enunciado englobante, possuindo um modo de existência realizado.

12 Cabe aqui a qualificação de "televisivo", pois admitimos que em todo projeto transmídia há uma mídia/ plataforma que serve de referência para o desenvolvimento das estratégias (mídia regente). No projeto "televisivo" transmídia, a mídia de referência é a televisão; no "cinematográfico" transmídia, o cinema, e assim por diante. 
programa e programação, agora temos o desafio de entender a natureza hipertextual do próprio objeto de estudo, levando em conta a relação cada vez mais estreita entre televisão e Internet. Os modos de interação que têm lugar nesse tipo particular de manifestação hipertextual - o texto televisivo transmídia - correspondem às práticas textuais de agenciamento. Nos textos televisivos transmídias — entre eles, as telenovelas observamos preliminarmente dois grandes tipos de práticas textuais de agenciamento chamadas de "articulação" e "atuação", as quais remetem, genericamente, ao desempenho dos destinatários-consumidores, sempre envolvendo algum tipo de intervenção "sobre" ou "a partir" dos conteúdos que lhe foram propostos pelo destinador-produtor.

As práticas textuais de "articulação" exigem a disposição do fã para buscar, articular e associar conteúdos complementares ou adicionais em outras plataformas, estabelecendo, nesse exercício, novas relações de sentido. O "trabalho" de articulação do fã consiste, basicamente, no estabelecimento das relações entre as várias unidades englobadas que, ao serem interrelacionadas, compõem o texto englobante transmídia. Buscar e conectar essas partes que formam o todo é, neste caso, o modo de agenciamento proposto ao fã telespectador, considerando que estamos diante de enunciados englobados acabados ou "completos". Esse tipo de prática textual não exige uma intervenção direta dos fãs nos conteúdos, mas pressupõe justamente a articulação “entre" os conteúdos ofertados. Considerando que estamos diante de uma manifestação de caráter hipertextual, parece pertinente pensar esse "trabalho" demandado do fã também nos moldes de uma "navegação", na qual ele se move de um conteúdo a outro, entre uma plataforma e outra, atualizando o percurso proposto. O trabalho consiste, nesse caso, na (re)operação do percurso hipertextual e interpretativo tributário da relação englobado/englobante.

Para Jenkins (1992), fãs são, antes de mais nada, “caçadores” de textos e este é, sem dúvida, um atributo desse tipo de consumidor de mídia que sustenta as práticas textuais de agenciamento de qualquer projeto transmídia. Booth (2010) também aponta o movimento “entre" os textos como uma prática característica dos fãs e propõe descrevê-la a partir da noção de intertextualidade. Embora o seu ponto de partida seja as ideias de Julia Kristeva ${ }^{13}$,

\footnotetext{
${ }^{13}$ Kristeva nomeou como "intertextualidade" o que Bakhtin chamou de "dialogismo". O termo, porém, nunca foi utilizado pelo próprio Bakhtin (FIORIN, 2006, p. 51-52). Segundo Kristeva, para que ocorra intertextualidade, é necessário que o leitor reconheça a presença de outro texto ou fragmentos produzidos anteriormente, os quais estabeleçam relação com o texto lido. O termo passou a ser usado depois, em acepção ainda mais ampla, para designar, genericamente, a relação, a associação ou o movimento entre textos.
} 
Booth faz um uso mais livre do conceito de "intertextualidade" para descrever as conexões transmídias por meios das quais os fãs relacionam aspectos de um texto com de outros. Em procedimentos de intertextualidade, o que está em jogo é, em outros termos, o "trabalho" da associação de conteúdos, que tanto pode ser considerado um fim em si mesmo - caso em que identificamos o tipo de prática denominada de articulação - quanto pode ser pensado como uma etapa necessária a algumas práticas textuais de atuação ${ }^{14}$.

As práticas textuais denominadas aqui "atuação" exigem a intervenção direta dos espectadores "nos" conteúdos para que estes se "realizem". Nesse caso, estamos diante de enunciados que se fazem incorporando o próprio ato de enunciação como parte daquilo que os define como tal. Ou seja, o agenciamento por parte do enunciatário é parte constitutiva de um tipo particular de enunciado, proposto deliberadamente pelo enunciador como inacabado e "aberto" às intervenções (do enunciatário) a partir das quais é atualizado. Esse tipo de prática pode ser considerado, genericamente, como uma "resposta" do fã telespectador às convocações contidas no próprio texto transmídia: participação em enquetes, concursos, campanhas, jogos, envio de fotos, vídeos, opiniões etc. Por mais distintas que sejam, essas "respostas" configuram sempre uma performance do fã telespectador no interior do próprio texto - uma atuação no texto, portanto. Essas práticas textuais de atuação podem ser pensadas, em outros termos, como procedimentos de "intertextualidade", tal como tratada por Booth (2010, p. 56). Ele a entende como a capacidade do documento digital de ofertar informações que voltam para alimentar a si mesmo, a partir de uma dinâmica de reciprocidade na troca de informações, ou seja, o documento tanto oferece quanto recebe informações como "resposta" dos seus "leitores" e é nessa dinâmica de troca que ele próprio se constrói.

Nos projetos transmídias, essa "resposta" pode ser pensada de modo mais amplo como qualquer procedimento por meio do qual o fã telespectador produz um conteúdo (elemento textual) que participa de algo maior (o texto propriamente dito) ofertado pelos

\footnotetext{
${ }^{14}$ Admitimos aqui que o "trabalho" de "articular" os conteúdos é o que permite, em muitos casos, que o fã telespectador venha a "atuar" sobre eles. Na novela "Cheias de Charme" (2012), que contou a história de um trio musical formado por empregadas domésticas (Empreguetes), temos um exemplo: na trama, os fãs fizeram uma campanha pela Internet em prol da libertação das heroínas, as quais haviam sido presas graças às trapaças da sua rival, a cantora brega Chayene. Os fãs telespectadores de "Cheias de Charme" foram convidados a aderirem, na vida real, à campanha lançada pelo site oficial do programa. Esta participação na campanha \#empregueteslivres, no entanto, não seria possível sem que, antes, estes fãs telespectadores se dispusessem a articular os conteúdos da TV e Internet.
} 
produtores: um vídeo enviado para um site, uma postagem em um perfil aberto numa rede social etc. As práticas textuais de atuação correspondem, em suma, à produção do que consideramos "conteúdos habilitados" por serem gerados pelos consumidores a partir de apelos contidos no próprio projeto transmídia ${ }^{15}$. Esses podem ser "autorizados", uma vez que são oriundos de condições, regras e orientações ditadas pelos produtores (via de regra, nos sites, blogs, perfis institucionais etc.). Funcionam, geralmente, dentro de espaços "oficiais" nos quais costuma haver um monitoramento, que busca manter um controle enunciativo capaz de assegurar o alinhamento da participação dos consumidores com os objetivos estratégicos dos destinadores-produtores.

Há, no entanto, conteúdos produzidos pelos consumidores, a partir de um texto transmídia existente, que circulam fora de tais espaços estratégicos da produção e que, consequentemente, escapam mais facilmente às tentativas de controle enunciativo. São conteúdos que estamos qualificando como não habilitados ou "não autorizados". Estes últimos podem, naturalmente, ser dissonantes de valores, objetivos e estratégias do projeto transmídia. Quando é esse o caso, torna-se bem mais fácil dissociá-los das estratégias transmídias. Pode ocorrer, no entanto, o contrário: apesar de surgirem sem uma tutela dos produtores de mídia e circularem em espaços "não oficiais", eles podem estar perfeitamente alinhados com os objetivos do projeto transmídia, reforçando ou mesmo desdobrando as suas estratégias. Quando isso ocorre, as fronteiras se embaralham mais facilmente. Entretanto, quer estejam alinhados ou não com os objetivos do projeto transmídia, não os consideramos, para fins de análise, como manifestações das práticas textuais de agenciamento, pois, uma vez que não foram propostos como parte integrante da estratégia de produção, não podem ser pensados a rigor como constituintes do "texto transmídia”, nos termos em que definimos aqui. São parte, no entanto, do universo interacional que se desenvolve em torno do texto transmídia ${ }^{16}$.

\footnotetext{
15 Recuperamos novamente aqui postulações apresentadas em Fechine et al. (2013), que podem ser encontradas de modo mais desenvolvido em: <http://obitelbrasil.blogspot.com.br/>. Acesso em: 1 nov. 2014.

${ }^{16}$ Consideramos, nesse caso, que toda a produção que estamos chamando de "não autorizada", embora não seja parte do projeto transmídia - e ainda mais especificamente do texto transmídia - é parte do universo discursivo que se forma em torno dele. Entendemos por "universo discursivo" um conjunto de discursos que interagem em dada conjuntura e se influenciam reciprocamente (CHARAUDEAU; MAINGUENEAU, 2008, p. 91). Inseridos nesse universo discursivo, os conteúdos "autorizados" e "não autorizados", postos em circulação "pelo" e "a partir" do projeto transmídia, podem ser identificados a distintos regimes de interação entre produtores e fãs. É nessa dinâmica entre os regimes que se constrói, por sua vez, o universo interacional transmídia (cf. FECHINE, 2014).
} 
A compreensão e a análise dessa vasta produção multiplataforma de conteúdos "não autorizados" ou "não oficiais" em torno dos programas televisivos desafiam os pesquisadores de Comunicação e demandam, inclusive, uma revisão dos protocolos metodológicos dos estudos de recepção, de modo a dar conta desse consumo transmídia de conteúdos. Consideramos, no entanto, que, mesmo estando focada sobre o "trabalho" dos fãs telespectadores, a etapa de pesquisa que temos a enfrentar é ainda parte da compreensão do modelo de produção televisiva transmídia, uma vez que o que nos interessa é a cooperação textual, ou seja, as modalidades de intervenção "no" e "a partir" de um texto — um texto englobante que se faz em ato, contando com a articulação e/ou atuação do fã telespectador.

Cabe ressaltar, por fim, que a noção das práticas textuais de agenciamento, que sustenta essa abordagem, é apresentada em estágio ainda exploratório, devendo ser posta à prova no decorrer da pesquisa empírica. Apesar do caráter provisório, a descrição geral dos procedimentos de articulação e atuação esboçada deve orientar a observação dos conteúdos produzidos pelos fãs telespectadores de telenovelas em busca de uma nova categorização ${ }^{17}$, a qual nos permita sistematizar e delimitar melhor a produção transmídia em sua dupla conformação, as estratégias e as práticas textuais envolvidas no projeto. Estamos cientes que, na realização desta observação, as categorias analíticas que presidem a observação práticas de articulação e atuação — podem ser modificadas pelo objeto observado dentro do processo de determinação recíproca que caracteriza a abordagem metodológica, cujas conceituações de bases foram aqui apenas esboçadas.

17 Referimo-nos aqui à categorização dos conteúdos resultantes dessas práticas textuais de agenciamento, segundo um caminho semelhante ao que foi realizado a partir da sistematização de estratégias (FECHINE et al., 2013). 


\section{Referências}

BOOTH, Paul. Digital fandom. New Media Studies. New York: Peter Lang, 2010.

CHARAUDEAU, Patrick; MAINGUENEAU, Dominique. Dicionário de análise de discurso. Tradução de Fabiana Komesu (Coord). 2 ed. São Paulo: Contexto, 2008.

DELWICHE, Aaron; HENDERSON, Jennifer (Eds). The participatory cultures handbook. New York: Routledge, 2012.

DUFFETT, Mark. Understanding fandom. An introduction to the study of media fan culture. New York/London: Bloomsbury, 2013.

EVANS, Elizabeth. Transmedia television. Audiences, new media, and daily life. New York/London: Routledge, 2011.

FECHINE, Yvana. Interações discursivas em manifestações transmídias. In: FECHINE, Y. et al. (Orgs). Semiótica nas práticas sociais: Comunicação, Artes, Educação. São Paulo: Estação das Letras e Cores, 2014.

- Televisão transmídia: conceituações em torno de novas estratégias e práticas interacionais da TV. Anais do XXII Encontro Anual da Compós (Associação Nacional dos Programas de Pós-Graduação em Comunicação). Salvador, BA: Universidade Federal da Bahia (UFBA), 2013.

FECHINE, Yvana et al. Como pensar os conteúdos transmídias na teledramaturgia brasileira? Uma proposta de abordagem a partir das telenovelas da Globo. In: LOPES, Maria Immacolata Vassalo de (Org.). Estratégias de transmidiação na ficção televisiva brasileira. Porto Alegre: Sulina, 2013. Disponível em: <http://obitelbrasil.blogspot.com.br/>. Acesso em: 01 nov. 2014.

FIORIN, José Luiz. Introdução ao pensamento de Bakhtin. São Paulo: Ática, 2006.

FLORES, Jesús; PORTO, Denis. Periodismo transmedia. Madrid: Editorial Fragua, 2012.

JENKINS, Henry. Textual poachers: television fans and participatory culture. New York: Routledge, 1992.

. Transmedia storytelling. Technology review. 15 de janeiro de 2003. Disponível em: <http://www.technologyreview.com/biomedicine/13052/page3/>. Acesso em: 02 fev. 2009.

Confronting the challenges of participatory culture: media Education for the $21^{\text {st }}$ Century (part one). 20 de outubro de 2006. Disponível em: $<$ http://henryjenkins. org/2006/10/confronting_the_challenges_of.html\#sthash.Z3zuFS3V.dpuf>.

Acesso em: 24 jan. 2014. 
. Cultura da convergência. Tradução de S. Alexandria. São Paulo: Aleph, 2008.

. The aesthetics of transmedia: in response to David Bordwell (part one). 10 de setembro de 2009. Disponível em: <http://henryjenkins.org/2009/09/the_aesthetics_of_ transmedia_i.html>. Acesso em: 02 fev. 2009.

JENKINS, Henry; FORD, Sam; GREEN, Joshua. Spreadable media: creating value and meaning in a networked culture. New York: New York University Press, 2013.

LOPES, Maria Immacolata Vassalo de (Org.). Estratégias de transmidiação na ficção televisiva brasileira. Porto Alegre: Sulina, 2013.

SANDVOSS, Cornel. Quando a estrutura e a agência se encontram: os fãs e o poder. Tradução de Simone do Vale. Ciberlegenda: Revista Eletrônica do Programa de Pósgraduação em Comunicação - PPGCOM/UFF, n. 28, 2013. Disponível em: <http://www. uff.br/ciberlegenda/ojs/index.php/revista/issue/view/A\%20Cultura $\% 20 \mathrm{f} \% \mathrm{C} 3 \% \mathrm{~A} 3 \% 20$ na\%20era\%20das\%20m\%C3\%ADdias\%20digitais/showToc>. Acesso em: 01 nov. 2014.

SHIRKY, Clay. A cultura da participação: criatividade e generosidade no mundo conectado. Tradução de Celina Portocarrero. Rio de Janeiro: Zahar, 2011. 